\title{
Métodos de investigación en la comunicación y sus medios
}

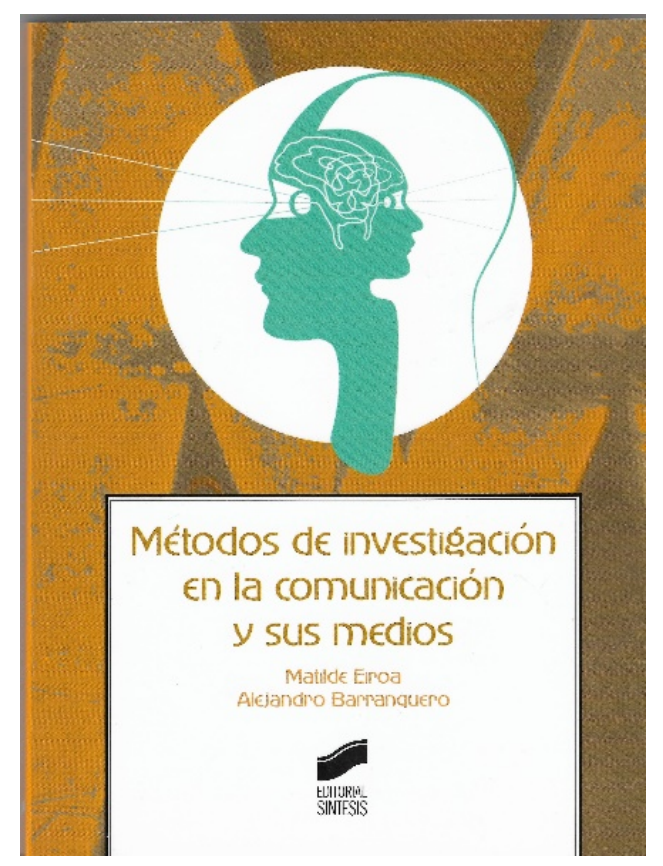

DOI: http://dx.doi.org/10.12795/Ambitos.2019.i45.17
Métodos de investigación en la comunicación y sus medios

Matilde Eiroa y Alejandro Barranquero

Editorial Síntesis, S.A, 2017, Madrid, 2017

208 páginas

Reseña por Elena Ruiz Cabezuelo

Métodos de investigación en la comunicación y sus medios es una obra de Matilde Eiroa, Doctora en Historia Contemporánea y profesora titular de la Universidad Carlos III de Madrid; y de Alejandro Barranquero, Profesor Ayudante Doctor en el Departamento de Periodismo y Comunicación Audiovisual de la Universidad Carlos III de Madrid, donde imparte asignaturas de teoría e historia de la comunicación y metodologías de la investigación. 
Se trata de una edición académica que esboza y explica de forma sencilla y asequible los principales métodos de investigación en el ámbito de la comunicación y sus medios, con un enfoque de praxis metodológica. Este enfoque se ve especialmente representado a través de los ejercicios prácticos que se plantean al final de cada uno de los apartados que conforman el libro. En ellos, se ofrecen preguntas y actividades encaminadas a favorecer la comprensión y asimilación de los conocimientos previamente expuestos por parte del lector.

La obra se divide en tres partes:

La primera parte plantea los conceptos básicos en investigación, empezando por el desarrollo del método científico y continuando con las técnicas propias del mismo. En este apartado se explica, de forma concisa y sencilla, cómo seleccionar y delimitar un tema-problema de investigación, plantear los objetivos y la selección del objeto de estudio; así como establecer la hipótesis, las preguntas de la investigación y la elección de un marco teórico.

La segunda parte ahonda en las metodologías de investigación, desarrollando el método cuantitativo y el cualitativo. El método cuantitativo aparece representado de forma muy descriptiva, pero se limita a la explicación de la obtención de datos a través de técnicas como la encuesta. En este sentido, se entiende que el grueso del segundo apartado de este título haya cobrado especial protagonismo en la exposición del método cualitativo, puesto que alberga mayor complejidad. En primer lugar se presenta de forma explicativa una serie de conceptos básicos, que darán paso a apartados en los que se trata con mayor precisión las distintas posibilidades que brinda la elección del método cualitativo como forma de estudio.

Entrando en materia comunicativa, este apartado incluye una serie de puntos en los que se estudia el comportamiento y las interacciones comunicativas a través de la observación y de sus variantes, como métodos científicos; se hace una introducción al análisis de mensajes y de discursos; y se establecen las pautas para examinar las dinámicas periodísticas tanto en prensa escrita como en información digital.

La tercera, y última parte, hace un repaso de los nuevos métodos surgidos como consecuencia de la llegada de la era de la tecnología, y más concretamente de Internet. Ambos han supuesto la necesidad de ampliar el estudio metodológico y la investigación al ámbito digital, y la renovación de las tendencias de investigación en materia de comunicación. 
Teniendo en cuenta lo anterior, se hace necesario destacar el apartado referente a los métodos cuantitativo y cualitativo- y especialmente a este último- ya que se plantea como una guía clara y concisa para facilitar la labor del investigador. Se trata de un punto muy interesante debido a que se establecen y se indican los pasos necesarios para llevar a cabo una investigación, lo cual supone una gran ayuda para la iniciación en el mundo de la investigación científica y académica.

Por otro lado, también resulta relevante la visión aportada durante el desarrollo del tercer y último apartado, en el que se aborda "Internet como objeto de estudio y como recurso de investigación, técnicas aplicadas al análisis de las redes sociales, el estudio de otros formatos digitales usados por profesionales y público en general, y, finalmente, una aproximación a la investigación de los hipervínculos", imprescindible para el entendimiento de la realidad y del mundo que habitamos. 